\title{
Silvio Waisbord: Diversidade e fragmentação - O campo da comunicação como uma pós-disciplina e seus desdobramentos na contemporaneidade
}

\section{Silvio Waisbord: Diversity and fragmentation - The field of communication as a post-discipline and its developments in contemporary times}

\author{
Entrevista com SILVIO WA ISBORD \\ Por ELIZABETH SA A D ${ }^{a}$ \\ Universidade de São Paulo, Programa de Pós-Graduação em Ciências da Comunicação. São Paulo - \\ SP, Brasil \\ Por DANIELA OSVALD RAMOS \\ Universidade de São Paulo, Programa de Pós-Graduação em Ciências da Comunicação. São Paulo - \\ SP, Brasil
}

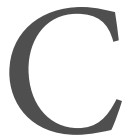

IÊNCIAS DA COMUNICAÇÃO e digitalização construíram uma relação indissolúvel na medida em que os processos sociais, econômicos, organizacionais e institucionais assumiram as tecnologias digitais de informação e comunicação como meio de conexão e operação. É possível afirmar que o campo tem atualmente um papel de centralidade no tecido social. Ao mesmo tempo, ao se fazer presente nos demais campos, correlatos ou não, coloca-se como transversal, atuando como agregador social.

Tem-se claro que o estudo acadêmico da comunicação e suas aplicações ganha importância, fazendo com que a pesquisa, a difusão e o ensino acompanhem inovações, mudanças e ressignificações de conceitos, ontologias e abordagens. Assim, como poderíamos caracterizar as ciências da comunicação na contemporaneidade?

Muitos questionamentos foram abordados pelo professor doutor Silvio Waisbord em seu recente livro Communication: A Post-Discipline (2019), ainda não traduzido para o português, obra que nos inspirou para sua entrevista em MATRIZes.

O professor Waisbord é sociólogo de formação desde sua licenciatura na Universidad de Buenos Aires, seguindo para mestrado e doutorado na DOI:http://dx.doi.org/10.11606/issn.19\$2-\$160.v15i1 p1 25-143 V.15 - № 1 jan./abr. 2021 São Paulo - Brasil WAISBORD I SAAD I RAMOS p. 125-143
${ }^{a}$ Professora titular sênior do Departamento de Jornalismo e Editoração da Escola de Comunicações e Artes da Universidade de São Paulo e do Programa de Pós-Graduação em Ciências da Comunicação (PPGCOM) na mesma unidade. Orcid: https://orcid. org/0000-0002-4020-7116. E-mail: bethsaad@usp.br

${ }^{\mathrm{b}}$ Professora no Departamento de Comunicações e Artes da Escola de Comunicações e Artes da Universidade de São Paulo e do Programa de Pós-Graduação em Ciências da Comunicação (PPGCOM) na mesma unidade. Orcid: https:// orcid.org/0000-0001-7687567X. E-mail: dramos@usp.br

MATRIZes 
${ }^{1}$ No original: "The dream of a common field, somewhat unified by common ontology, theoretical canon, and the scientific method, is out of reach". Essa e demais traduções, das autoras.

${ }^{2}$ No original: "Communication was multidisciplinary before multi- and interdisciplinary became important trends in academia”.
San Diego University. Atualmente é diretor e professor na Escola de Mídia e Assuntos Públicos, George Washington University. Publicou mais de 200 artigos em periódicos acadêmicos de diferentes línguas, além de nove livros autorais ou organizados, dos quais o mais recente foi lançado em março deste ano The Routledge Companion to Media Disinformation and Populism (Tumber \& Waisbord, 2021), sem tradução para o português.

Nosso entrevistado transita por múltiplas temáticas do campo, em especial os communication studies, o jornalismo, a sociologia da mídia e os aspectos de transformações globais da sociedade e respectivas relações com nosso mundo da comunicação. Waisbord é um scholar de referência, especialmente por sua experiência de mais de dez anos como editor-chefe do Journal of Communication, publicado pela International Communication Association (ICA), e do International Journal of Press/Politics, editado pela Sage Publications.

Tais experiências, lendo, redigindo e editando centenas de artigos acadêmicos, interagindo com autores de todos os continentes e vertentes teóricas, deram ao professor uma visão crítica e lúcida sobre o cenário recente dos estudos em ciências da comunicação e suas perspectivas futuras.

Não por acaso cunhou a comunicação como uma pós-disciplina, retratando sua diversidade e fragmentação resumida numa frase lapidar de seu livro: "O sonho de um campo único, de alguma forma unificado por uma ontologia, cânones teóricos e métodos científicos, é algo inatingível”' (2019, Cap. 2, seção Should we worry, para. 1). E, não por acaso, conversamos com o professor Waisbord sobre os rumos de nosso campo, fundado num histórico de suas origens multidisciplinares nas ciências sociais e que, em sintonia com sua proposição - “a comunicação foi multidisciplinar, antes que a multi e a interdisciplinaridade se tornassem tendências importantes na academia"2 (2019, Cap. 1, seção Why fragmentation, para. 1) - chega a nossos dias mais próxima de uma interdisciplinaridade, apenas.

Nosso entrevistado deixa claro que tal dissonância não é exatamente um problema, mas se constitui num debate que põe em contínua discussão as relações acadêmicas, as vertentes e abordagens e um embate entre olhares amplos e aqueles hipersegmentados, que perpassam os estudos de comunicação mundo afora. Buscamos, nesta entrevista, passar pelos múltiplos temas abordados em Communication: A Post-Discipline (Waisbord, 2019) - os objetos e métodos; a tendência de uso de métodos quantitativos para pesquisa como um parâmetro de publicação em periódicos internacionais referenciados; sua proposta de taxonomia para conceituar o campo; os impactos que vivenciamos por conta da digitalização, reverberados, por exemplo, na desinformação, em violências e polarizações e na modulação algorítmica; a formação acadêmica dos profissionais 
de comunicação e suas propostas de esperança para que possamos olhar para os estudos de comunicação como um meio de discussão para questões comuns, independentemente de regionalidades e localidades: o papel da comunicação na alfabetização midiática, nas mudanças climáticas, nas distopias digitais, nos aspectos de raça, gênero e etnias.

Entrevistamos o professor Waisbord pelo do Zoom, em meio ao distanciamento pandêmico, ele em sua residência em clima primaveril de Washington e nós no outono paulistano, mas todos com sensação de verão. O resultado foi caloroso, possibilitando que transitássemos entre formalidade temática e aqueles aspectos mais informais e pessoais que permeiam a rotina de acadêmicos do campo da comunicação. Todos concordamos que, para qualquer ressignificação do campo, será preciso usar de muita imaginação.

MATRIZes: Seu livro e sua experiência pessoal mostram, com autoridade, quão fragmentados são o campo acadêmico e a pesquisa em comunicação em todo o mundo. As questões regionais e culturais, tradições acadêmicas e o comportamento dos pesquisadores e acadêmicos são alguns pontos que reforçam, em suas palavras, um estado babeliano e um campo manqué. Você considera que a identidade da comunicação continuará sendo a de uma área multitudo ou existem alternativas para o surgimento de um campo efetivo?

Waisbord: Penso que a resposta é absolutamente sim. E a razão é porque as dinâmicas que temos observado historicamente estão mais fortes do que nunca. Por um lado, não existe uma forte tendência de contrafragmentação nos estudos comunicacionais. Não há muitas pessoas realmente trabalhando para tentar unir esses estudos em torno de um conjunto compartilhado de questões ou uma visão comum ou tentando reunir as diferentes linhas de pesquisa e reflexão dentro dos estudos de comunicação. E, por outro lado, constantemente haverá novas áreas surgindo e contínuas especializações, assim, mesmo depois de poucos anos desde a redação do livro, continuo a ver, inclusive, o aprofundamento dessas tendências. E, também, é o contexto mais amplo do que estava acontecendo nas ciências em geral, as humanas e as sociais. Creio que é uma proliferação constante de novas áreas de pesquisa, novos léxicos, novas teorias.

Estamos bem longe desse sonho de ter disciplinas e campos bem definidos. Isso acabou, não vai mais voltar nas ciências sociais e humanas, se é que algum dia foi possível, acho que nunca, pois a ideia de uma ciência integrada vem de um modelo de ciência muito, diria, modernista do início do século XX e, especialmente, das ciências sociais e humanas. Quer dizer, nunca existiu realmente. E uma das razões é porque esse tipo de modelo científico requer um cânone dominante, um corpo de conhecimento que seja fundacional, e nos estudos 
de comunicação, por exemplo, é muito difícil hoje concordar com um cânone fundamental que defina as linhas, as discussões, as teorias e os conceitos para todo o campo. Isso nunca existiu e, hoje, é ainda mais difícil, dado o que está acontecendo no conhecimento acadêmico global. Então, acho que é um estado de coisas, não apenas exclusivo dos estudos de comunicação, mas também de outras disciplinas, que irá permanecer.

MATRIZes: Existem muitos prefixos possíveis cunhados pelos acadêmicos para caracterizar os estudos da comunicação - uma pós-disciplina, uma não disciplina, uma ciência do comum, por exemplo. Qualquer que seja o prefixo, você considera a comunicação como central e transversal nos diferentes saberes, especialmente no momento presente. Como esse protagonismo poderia coexistir e colaborar com as ortodoxias de outras áreas?

Waisbord: Os estudos da comunicação se cruzam constantemente com outras disciplinas e campos, e é isso que, acredito, torna as comunicações tão ricas, tão empolgantes, de modo que não dá para ficar entediado: as questões de pesquisa mudam constantemente. As abordagens mudam constantemente. Sua maneira de expandir as pesquisas anteriores muda. Porque a comunicação é um fenômeno que de alguma forma está em constante mudança, não apenas por causa da tecnologia, não simplesmente porque muito do que estudamos está ligado às tecnologias da informação e da comunicação e, portanto, à medida que as tecnologias mudam, o que estudamos também muda constantemente. Acredito que, por causa dessa posição singular, as ciências sociais e humanas sempre se ocuparam dos estudos da comunicação: estão na encruzilhada de diferentes tendências, conversações e debates. Não acredito que a ortodoxia jamais tenha sido estável nos estudos de comunicação, em função da natureza do objeto de nosso estudo. Isso é ontológico, se você preferir - uma bênção -, ou uma característica desses estudos, e é por isso que neles você encontra pessoas que vêm de tradições disciplinares muito diferentes, que de alguma forma convergem em movimentos semelhantes?

Sua pergunta é sobre o protagonismo e essa é uma pergunta ligeiramente diferente. O protagonismo é, independentemente da resposta, se os estudos da comunicação são suficientemente reconhecidos por outras ciências e disciplinas, e isso sempre foi uma questão problemática. Teria que haver alguma pesquisa para verificar isso em outros campos e disciplinas, como ciência política, história ou sociologia. Pessoas que trabalham com questões de comunicação e informação e não necessariamente têm conhecimento da pesquisa em comunicação. E isso sempre existiu como um problema de determinadas formas, a comunicação sendo vista como um campo ou ciência inexistente, ou que as pessoas em outras 
disciplinas desconheciam. Isso é um problema. E isso, a meu ver, continua sendo um problema, e tem a ver com a questão do protagonismo. $O$ protagonismo não é apenas o que nós, pesquisadores da comunicação, decidimos, mas o lugar que ocupamos na academia, envolvendo-nos com outras disciplinas.

MATRIZes: Principalmente no Brasil, a comunicação não é aceita pelos empresários. Todas as áreas de comunicação aqui são alocadas em marketing. Então, temos algumas lutas para entender o que é comunicação e como ter um profissional que estuda comunicação atuando nessa área no mercado. É melhor trabalhar como jornalista ou como relações públicas, mas não como comunicador. Você consegue entender esse dilema?

Waisbord: Isso tem a ver com a ambivalência e a ambiguidade da comunicação como um conceito, porque ela significa tantas coisas diferentes, não apenas dentro dos estudos da comunicação, mas também fora deles. É impossível, de fato, unificar o que significa comunicação, das escolas de administração à ciência política e tudo mais, incluindo a ciência da computação. $\mathrm{O}$ que comunicação significa em certos aspectos é uma espécie de fardo, porque sempre precisamos explicar o que fazemos e o que é comunicação. E também porque nós mesmos não temos um consenso, discuto no livro: com a falta de consenso em torno da comunicação, ela pode ser vista como parte da riqueza do que estudamos, mas ao mesmo tempo é um desafio porque levanta essas questões sobre o que fazemos. Como gerenciamos as percepções que outros campos e disciplinas têm sobre os estudos da comunicação? Então, isso pode ser visto como uma força ou como um desafio. Entendo que intelectualmente é muito enriquecedor, mas em termos dos aspectos profissionais, institucionais, especialmente dentro das universidades, isso normalmente se torna um desafio, pois você precisa explicar aos outros o que fazemos, o que cobrimos e o que não abordamos.

MATRIZes: Essa falta de consenso é, talvez, por que a semiótica não se tornou o bloco unificador do campo dos estudos da comunicação?

Waisbord: Creio que o que aconteceu com a semiótica ocorreu com muitas outras vertentes de pensamento sobre a pesquisa. Ela acabou relacionada à comunicação, mas nunca se tornou o núcleo da área. A semiótica tradicional é bastante forte na América Latina, principalmente no Brasil, na Argentina e no México, mas derivando da tradição europeia, principalmente a francesa, da semiótica. Porém esse não é o caso dos Estados Unidos ou do Reino Unido, ou mesmo nos países nórdicos, nos quais a semiótica nunca teve aquela posição central em torno da qual os estudos de comunicação se desenvolveram. Nunca 
${ }^{3}$ No original: "Communication was multidiscilinary before multi- and interdisciplinary became important trends in academia”. foi o tronco ou a espinha dorsal dos estudos de comunicação. Nos Estados Unidos, os estudos de comunicação surgiram da pesquisa de opinião pública e de psicologia e, até certo ponto, da sociologia, mas nunca da semiótica.

Esse ainda é o caso de muitas das pesquisas produzidas na América Latina sobre os estudos da comunicação que se fundamentam na semiótica de uma forma que não ocorre, realmente, nos Estados Unidos. E, também, a semiótica teve na América Latina uma entrada precoce nos departamentos de literatura, mais do que nas comunicações, antes mesmo de os departamentos de comunicação serem estabelecidos. Desse modo, há muitas pessoas trabalhando em semiótica e comunicação saindo de uma tradição literária - pessoas que estudam literatura, linguística, igualmente. Nos Estados Unidos, essa tradição não existe, não é tão forte e definidora como na América Latina. Especialmente quando se olha para os estudos da comunicação globalmente, a semiótica tem uma presença muito diferente.

Você pode perguntar à maioria das pessoas que obtiveram um doutorado em comunicação nos Estados Unidos sobre Peirce ou sobre Barthes e eles não têm ideia de quem são essas pessoas - nenhuma tem ideia. A menos que as pessoas tenham estudado comunicação interpessoal, por exemplo, ou linguística, elas não saberão do que se trata. E você raramente encontrará revisa científicas de comunicação dos Estados Unidos publicando sobre semiótica, porque elas seguem essas linhas paralelas.

MATRIZes: Esta citação "A comunicação foi multidisciplinar, antes que a multi e a interdisciplinaridade se tornassem tendências importantes na academia"3 (Waisbord, 2019, Cap. 1, Seção Why fragmentation, para. 1) inicia sua proposta de taxonomia - conexão, diálogo, expressão, informação, persuasão e interação simbólica. Todos esses aspectos são reforçados em uma sociedade digitalizada e estão interligados para expressar nossas ações comunicativas contemporâneas. Você poderia comentar sobre os efeitos da comunicação (para o bem ou para o mal) diante da desinformação, desplataformização, modulação algorítmica para tendências de opinião pública, influenciadores de mídia social?

Waisbord: Essa é uma excelente pergunta. Todas essas abordagens, de alguma forma, sempre lidaram com as questões da desinformação ou propaganda enganosa e mentirosa. É possível estudar essas questões ao se entender as comunicações como conexão, diálogo, informação, expressão etc. Acho que, nesse momento, de certa forma, é uma outra rodada de abordagens muito semelhantes para a compreensão da comunicação, olhando para a desinformação ou o papel das plataformas de mídia social. Algumas dessas são questões 
antigas, não uma novidade. O que há de novo é a forma como isso acontece, a centralidade de novas formas de mediação e técnicas mais sofisticadas de propaganda e desinformação.

Mas, no fundo, algumas dessas questões não são tão novas, ou o modo como atravessam diferentes entendimentos sobre a comunicação. Na verdade, o recente livro que acabamos de publicar sobre a desinformação na mídia (Tumber \& Waisbord, 2021) é um bom exemplo, porque, de certa forma, há pessoas abordando essas questões a partir da perspectiva de entender a comunicação como informação, como persuasão e como expressão. Portanto, de certa forma, não é explícito. Não é feito de maneira deliberada, mas normalmente está subjacente ao que as pessoas entendem sobre o problema - quais são as causas, como definir essas informações ou como pensar em alternativas a elas.

O que é interessante nisso é quão profundamente o pêndulo oscilou, do otimismo tecnológico de quinze anos atrás para, agora, uma visão mais distópica da comunicação digital. Isso para mim é a parte mais interessante dessa tendência. Ao se observar o que foi escrito há apenas dez anos, digamos na época da Primavera Árabe, isso parece tão desatualizado, tão simplista. E não só porque a tecnologia evoluiu muito na última década. É porque os argumentos sobre a comunicação digital foram guiados mais pela esperança do que por evidências. Pela convicção que muitas pessoas tinham sobre a inerente benevolência do aumento da expressão, ao invés de preocupações com o quanto isso leva ao ódio, à vigilância, a todos os tipos de fenômenos distópicos: mais expressividade não removeria as questões sobre a concentração de propriedade da mídia; o fato de que a maioria de nós está falando globalmente em algumas poucas plataformas que têm um conjunto muito específico de regras, considerações e objetivos econômicos; quer dizer, todas essas questões não eram realmente centrais quando as pessoas tinham todas essas visões excessivamente otimistas sobre as tecnologias digitais - não apenas pessoas de direita, mas até mesmo pessoas de esquerda.

Para as pessoas de esquerda, toda a discussão era em grande medida sobre a promessa da noção geral de que mais expressão é mais democracia; mais democracia significa mais representação, mais reconhecimento dos direitos humanos. E isso é verdade, mas não é a única história. A história principal hoje não é que mais expressão, facilitada pelas plataformas digitais e tecnologias digitais, leva a mais representação ou mais direitos, e a razão é porque mais expressão acontece no contexto de estruturas de poder que não mudaram drasticamente e, portanto, ocorrem desenvolvimentos mais antidemocráticos e mais autoritários do que movimentos de expressão que alteram completamente as coisas. Em segundo lugar, percebemos que a expressão é insuficiente e que, na verdade, pode levar ao ódio. 
Conforme a expressão não leva ao reconhecimento ou à tolerância dos direitos das pessoas, o aumento dela, na verdade, conduz à restrição dos direitos de expressão que muitas outras pessoas têm. Essa, para mim, é uma das questões centrais: a incompatibilidade entre mais expressão e mais direitos humanos ou mais direitos comunicativos. Mais expressão sempre foi a causa de, digamos, liberais progressistas e radicais, e agora essa questão foi sequestrada pela direita. A direita de alguma forma parece ser a campeã de mais expressão, então todo o debate, a salutar conversação sobre a cultura do cancelamento, que infelizmente se tornou global, é um exemplo de como a direita - especialmente a extrema direita - sequestrou a noção de que mais expressão, mais liberdade de expressão é um bem, independentemente de qualquer outra coisa. E agora, a discussão que precisamos fazer na esquerda é que, na verdade, mais expressão contraria os direitos de expressão de outras pessoas, ou de outros direitos humanos, se for mais expressão como um veículo de ódio, para pisotear os direitos de outras pessoas. Você perguntou quais são os efeitos. Estou mais preocupado com as consequências do que, digamos, satisfeito com os resultados desses processos.

MATRIZes: Talvez a partir de agora e no futuro essas coisas possam se estabilizar, porque, como você falou, e nós concordamos, começamos com otimismo e agora não estamos de forma estruturada, talvez no futuro haja um centro, uma convergência, algum dia.

Waisbord: Creio que, de certa forma, nos prejudicamos bastante com o otimismo infundado de uma década ou quinze anos atrás. Não sou pessimista, mas, de certa forma, é difícil encontrar motivos fortes para recuperar o otimismo quando a situação atual é tão generalizada. Os maus exemplos, as situações antidemocráticas... É muito difícil. É sempre possível ter esperança, mas a questão é: como reconciliar os pressupostos normativos mentais com o que mostram as tendências empíricas? Elas mostram algo muito desagradável, certo? E, claro, o que aconteceu no Brasil é um excelente exemplo da convergência dessas tendências desagradáveis facilitada pelas tecnologias digitais. Portanto, a questão é que provavelmente o que precisamos fazer é ter muito mais conclusões contextualizadas do que conclusões que sejam apenas aspiracionais.

Acredito que o momento de dez, quinze anos atrás foi impulsionado mais por um argumento aspiracional "o que se gostaria que acontecesse", em vez do que realmente, com base nas evidências, poderia acontecer. E quando se vê a tendência de direita em tantos países, é difícil descobrir qual é a saída para essa situação em termos de efeitos, em termos de que as tecnologias digitais tendem principalmente a favorecer as perspectivas e posições autoritárias, políticas. 
Os usos mais progressivos, tendo a pensar, são os mais excepcionais; eles são importantes, mas tendem a ser as exceções e não a regra. Quando se olha para a maneira como os governos, não apenas na Rússia e na China, mas também em muitos países da América Latina, estão usando a internet, é difícil achar que as tecnologias digitais necessariamente levam a um impacto democrático mais significativo.

MATRIZes: Enquanto estamos falando sobre como a internet produziu diferentes perspectivas de vida em sociedade, vamos explorar um pouco mais essa questão antes de retornar à nossa discussão central. Em relação à crescente polarização política no mundo e à crescente mistura de táticas de comunicação violentas utilizadas por alguns atores sociais, como os políticos, as milícias digitais formadas por pessoas comuns, os grupos terroristas e os líderes com aspectos autoritários, você acredita que a comunicação está perdendo o poder de mediação social? Se sim, você acha que é possível que a violência em pouco tempo tenha se tornado uma nova dimensão dos estudos da comunicação, indo além de autores como Baudrillard (2000) e Virilio (1993)?

Waisbord: É impossível pensar em mediação sem comunicação, seja em macro ou microprocessos. Assim, quando há mediação há sempre comunicação e vice-versa, ou seja, utilizo os dois conceitos. Mesmo que se pense em comunicação interpessoal, a linguagem é uma forma de mediação. A comunicação, na minha opinião, por definição é mediação, não se trata apenas de mídia no sentido de tecnologia ou plataformas, simplesmente a forma como estamos nos comunicando agora, a linguagem, é o meio.

Penso que está implícito no que você disse. Creio que a violência sempre foi uma dimensão dos estudos da comunicação, porém não foi suficientemente reconhecida como uma dimensão central da comunicação. Portanto, isso vai muito além de Baudrillard e Virilio. A questão é que, em um mundo violento, a comunicação necessariamente tem um forte componente de violência, correto? Não importa quem é contra a violência ou quais são as causas da violência. Sempre há um forte componente de violência na comunicação. E a violência em si é uma forma de comunicar violência.

Quando as pessoas incitam a violência contra outras, essa é um modo de comunicação, não importa qual seja o episódio ou o ato de violência realmente. E, para mim, infelizmente, é tão poderoso, tão onipresente que é invisível quanta violência é intrínseca à comunicação. De certa forma, não temos teorias sobre isso, temos teorias da comunicação para a construção da paz. Não temos teorias da comunicação como forma de violência, embora isso seja - em grande parte da realidade - constituinte tanto da violência quanto da comunicação. 


\section{$\mathrm{E}$}

${ }^{4}$ Enviamos perguntas prévias a Silvio Waisbord, citando o sociólogo francês Michel Wieviorka e seu livro Violence: A New Approach (2009), no qual ele relata o papel da televisão na cobertura dos relatos dos judeus no holocausto pósSegunda Guerra Mundial, contribuindo para o que chamou de "emergência das vítimas"; ele também aponta a interdependência, estudada também por outros, entre terrorismo e mídia, discute o papel do rádio no processo de desumanização da minoria Tutsi em Ruanda, cruelmente executada pelos Hutus, e diz que, por meio da abordagem sociológica clássica, a influência da mídia na perpetração de muitas violências nunca foi comprovada. Também observamos que "Apesar da falta de comprovação científica de que a mídia em geral possa influenciar os atos de violência, parece que a violência e a comunicação estão ligadas de muitas formas, e que essa relação entre elas como campos está crescendo na era digital”.

Quer dizer, creio que o trabalho das pessoas que vocês mencionaram ${ }^{4}$ nos lembra como nossas sociedades são violentas e como a comunicação é violenta em todos os lugares. Não é apenas nas notícias; ela se espalha por toda parte na sociedade, nos lares, nas famílias, nas instituições. E creio que o que vocês levantaram é um ponto cego muito interessante, que é o quão raramente pensamos a violência como incorporada em atos de comunicação cotidianos, ao invés de violência em termos de uma cobertura de violência ou a que afeta os jornalistas. A violência é intrínseca em muito do que acontece na comunicação.

Hoje, o que estamos vendo é que a internet e a comunicação digital estão tão impregnadas de violência que não podemos mais ignorar. Quando o ódio digital está tão difundido na internet, isso nos lembra que em todos os lugares na internet a comunicação é violência, ou a violência é uma forma de comunicação. Essa comunicação é um ato violento, na forma como as pessoas atacaram especialmente as mulheres, negros, sobretudo por causa da religião, etnia ou de sua sexualidade. Nisso, de certa forma, a comunicação digital nos lembra o quanto e como a violência é central na comunicação cotidiana. Não é surpreendente que tantas pessoas estejam tentando entender isso! Bem, o ódio digital é um reflexo do ódio off-line. A questão é que, se facilita, torna mais fácil ser abrangente para ser massivo.

Mas, de alguns modos, reflete as sociedades em que sempre vivemos. Desculpe ser tão depressivo. Estou trabalhando em um projeto agora com Julie (Possetti) e outras mulheres sobre isso, e é tão massivo, tão pervasivo... E tanto violência destrutiva, quando os leitores ou pessoas sem experiência se envolvem com o jornalismo: há tanta violência no que está sendo dito. Há muita violência nas seções de comentários dos jornais on-line. Então, de certa forma, isso está lá. Costumávamos crer que era algo localizado, que fora relegado a uma parte da sociedade. $\mathrm{O}$ tremendo acesso a plataformas de internet mostra o quão massivo é.

MATRIZes: Em termos concretos, podemos dizer que a violência está dentro da natureza humana. Nós comunicamos isso...

Waisbord: Certo, e também porque nossas sociedades fomentam a violência continuada. Costumávamos pensar que a expressão, como valor democrático, estava relacionada à questão da publicidade e da visibilidade - que quanto mais as pessoas se expressassem seria uma forma de se tornarem mais públicas e mais visíveis na sociedade e na democracia para o reconhecimento de suas demandas e de seus direitos. Estamos em um momento agora em que mais visibilidade, mais publicidade, no sentido habermasiano, é perigosa. A publicidade não conduz necessariamente a nada democrático. Mais publicidade leva a mais vulnerabilidade e afeta pessoas que já são muito vulneráveis nas 
sociedades. Quanto mais vulneráveis off-line, são ainda mais vulneráveis on-line, quanto mais públicos, mais visíveis são. Se é uma mulher ou uma pessoa gay ou queer, ou membro de uma minoria étnica em determinado país, e se for visível como político, como ativista, como celebridade, como jornalista, como um acadêmico - a visibilidade se torna vulnerabilidade.

Precisamos repensar essa questão de que expressão é igual a mais democracia, mais reconhecimento. E precisamos pensar que, em alguns casos, as pessoas optam por não ser públicas, não se expressar, porque querem se proteger. Não por causa da censura. Porque vivemos em uma sociedade violenta na qual alguém se torna mais público, mais visível, se se expressa mais. Torna-se alvo de ataques e isso é devido à violência inerente à sociedade em que vivemos. E a violência não é apenas a econômica no capitalismo; são diferentes formas de violência. Violência é violência, seja motivada por questões econômicas, ou por qualquer outra coisa, ou, como vocês disseram, pela "natureza humana". Então, a questão com que tentamos lidar é muito difícil: ao concordar com Nietzsche e acreditar que "a violência é a força motriz do ser humano", colocá-la junto com mais expressão é algo muito complicado e leva a resultados bastante distópicos.

A ideia de mais expressão em sintonia com alguma benevolência inerente à humanidade movida pelo respeito, pela tolerância, pela compreensão, pela escuta, pelo diálogo. Mas se essas condições estiverem faltando, o que se tem são desenvolvimentos muito preocupantes. Em Habermas e em muitas outras teorias, existem certas condições para o diálogo, para a escuta, para o respeito pelas normas - por normas que não existem! - na sociedade em geral. Quando essas normas faltam, mais expressão ou mais instabilidade conformam violência.

MATRIZes: Podemos dar um pequeno exemplo sobre isso? Durante o evento de segurança do jornalismo de Oslo, em novembro de 2019, apresentamos um minidocumentário sobre a violência brasileira contra jornalistas e a situação política em nosso país. Decidimos não o divulgar em nossos grupos locais no Brasil devido ao dilema visibilidade-vulnerabilidade.

Waisbord: É isso. E essa é a realidade, e nós, acadêmicos, estamos menos expostos do que jornalistas, ativistas ou políticos. Mas essa é a realidade em que nós mesmos, como acadêmicos, nos censuramos na maneira como tornamos nossos trabalhos públicos, porque ninguém gosta de estar no centro desses enxames, desses ataques. Temos muito cuidado com o quão público somos, especialmente em um país autoritário. Mas, em países democráticos, agora também estamos fazendo a mesma coisa! Essa autorregulação de nossa expressão é feita no Facebook ou nas plataformas sociais o tempo todo. Por 
vários motivos, inclusive porque não queremos ser alvo de violência. Então, de volta ao ponto original, isso mostra basicamente o quanto esquecemos a questão dos efeitos da comunicação digital.

Os efeitos digitais foram de alguma forma intensificados, fortalecidos, ou incrementaram a violência em vez de aumentar qualquer bem. De certa forma, ainda estamos lidando com isso... a expressão que vem de Kant sobre "a madeira torta da humanidade". Há algo basicamente errado a nosso respeito e, de certa forma, poderíamos argumentar que é isso que as tecnologias digitais aumentaram - quero dizer, o modo como essas grandes corporações são administradas, com o desejo de maximizar dinheiro a partir do engajamento. Eles não se importam com os direitos humanos. Isso nunca é um fator determinante na maneira como eles organizaram os algoritmos ou configuraram as plataformas; eles só querem mais dinheiro e mais pessoas falando, mesmo que falem denegrindo outras pessoas.

MATRIZes: É verdade! Está certo, fizemos um pequeno (embora necessário) desvio do centro de nossa conversa. Voltemos a ele: há um conflito histórico entre a pesquisa em comunicação e a pesquisa em jornalismo. A academia brasileira enfatiza isso tanto nos currículos de graduação quanto em programas de pós-graduação e também nas interações dos acadêmicos. É um paradoxo que deve ser superado, principalmente em uma era de centralidade da comunicação?

Waisbord: É parte da complexidade da confusão que discutimos anteriormente. Que a pesquisa em comunicação e a pesquisa em jornalismo se desenvolveram em linhas paralelas com alguns cruzamentos, não sei se é um paradoxo. Creio que faz parte da noção de múltiplas camadas dos estudos de comunicação e mídia e dos estudos de jornalismo, que, de certa forma, é mais um desafio institucional. Porque muitos departamentos de jornalismo ao redor do mundo foram estabelecidos antes que os estudos de comunicação se consolidassem. E as escolas de jornalismo eram vistas como escolas profissionais, em vez de escolas de comunicação na intersecção das ciências humanas e sociais.

Bem, o Brasil é o melhor exemplo quando alguém está no jornalismo - as tradicionais escolas de jornalismo -, paralelo ao desenvolvimento da comunicação como campo de estudo ou de pesquisa. Porque o Brasil foi pioneiro no desenvolvimento de escolas de jornalismo e, afinal, há algumas sobreposições, mas ainda acho que existem diferenças importantes. Isso é mais um aspecto institucional do que, diria, uma questão epistemológica. Não sei se possamos superar isso, fazer melhor, não creio, porque penso que parte do jornalismo se 
relaciona principalmente a competências profissionais, que não necessariamente estão incorporadas nas teorias ou no pensamento da comunicação.

Então, sim, pode-se pensar conceitualmente sobre o jornalismo de uma perspectiva de comunicação, mas existem todos os tipos de questões que não são estritamente sobre a comunicação. Pode-se argumentar que muito do que o jornalismo faz é sempre comunicação quando se produz uma matéria, quando ela é editada, quando um vídeo é gravado, quando se edita um livro, que é sempre comunicação, mas normalmente é feito dentro dos limites do que significa ser jornalista, de questões profissionais sobre habilidades, sobre ética, sobre todos os tipos de questões que, de certa forma, são exclusivas do jornalismo. Então, eu os veria como uma prática e pesquisa que se sobrepõem, em vez de algo que pode ser unificado ou reunido. Isso é muito interessante sobre o Brasil, pois não consigo pensar em nenhum outro país da América que tenha escolas e estudos de jornalismo tão fortes, e uma tradição tão forte de escolas de comunicação, praticamente separados.

MATRIZes: Gostaríamos de falar sobre objetos e métodos de pesquisa. Nós (pesquisadores do Sul global, e especificamente brasileiros) estamos enfrentando agora o fardo de uma herança de pesquisa mais humanística contraposta à necessidade de métodos de pesquisa quantitativos amplamente utilizados na pesquisa estadunidense. Você considera que essa lacuna deve ser reduzida? Como?

Waisbord: Valorizo o legado da pesquisa humanista. Para mim não é um fardo, é um dos pontos fortes dos estudos de comunicação no Sul global, especialmente na América Latina. Por que valorizo tanto isso? Creio que é um reflexo de uma educação e formação intelectual mais ampla na América Latina, mas principalmente no Brasil. Minha sensação é que na América Latina lemos os estudos de comunicação de forma muito mais ampla, incluindo a tradição humanista. A história, a filosofia ou a ética ainda são um componente forte em muitas escolas de comunicação da região. Estamos mais fundamentados na maneira como pensamos a comunicação especificamente, mas também a comunicação em uma variedade de campos e disciplinas, em grande medida devido à tradição humanista.

Agora, o desafio é porque fazemos isso em um momento de popularidade dos métodos de pesquisa quantitativa, especialmente das amplas análises de dados, ciência computacional, pesquisa algorítmica. Acredito que, de certa forma, é uma nova rodada de um antigo desafio. O que fazer quando os métodos quantitativos são hegemônicos? Em termos de poder ou obtenção de fundos, o que fazemos com uma tradição mais humanista, teórica, epistemológica e metodologicamente? 
A lacuna sempre existiu. Agora temos outro terreno para esse hiato. Não sei se podemos reduzi-lo, se isso é possível, porque a razão remonta a uma das primeiras coisas que disse: não acho que muitas pessoas estejam interessadas em reduzir a lacuna. Em vez disso, o que precisamos é da aceitação de diferentes abordagens dessa diversidade epistemológica. Como a reconhecemos nas instituições, nas revistas científicas, nas escolas, nas conferências... O fato de as pessoas abordarem a comunicação de forma diferente, ontológica e epistemologicamente. Essa, para mim, é a maneira de abordar isso.

Pessoalmente, avalio que a ênfase nos métodos qualitativos muitas vezes esquece que a questão principal não é o método, a questão principal é "Qual é a questão?". Compreender em sua pergunta teórica qual é a questão da pesquisa - não é sobre o método. Sou sempre cauteloso e um tanto cético quanto a priorizar métodos, porque estamos colocando a carroça na frente dos bois. O que impulsiona a busca intelectual - o conhecimento acadêmico - são indagações sobre fenômenos teóricos ou empíricos. Essa deve ser a questão motriz - não o método -, o método é uma escolha que fazemos com base na experiência ou na maneira como pensamos, mas isso não deve substituir o debate sobre uma das questões importantes "Como pensamos na elaboração das perguntas?". Se fosse priorizar, essas questões surgem muito antes de se pensar sobre quaisquer questões metodológicas ou mesmo sobre o planejamento da pesquisa.

Então, sim, a internet oferece oportunidades para fazer grandes análises de dados por meio de metodologias quantitativas que são completamente novas e muito interessantes e ricas. Isso não exclui, digamos, as humanidades ou a tradição qualitativa das ciências sociais que fala sobre a importância de fazer as perguntas; é possível perguntar, responder às mesmas indagações por meio de metodologia qualitativa ou quantitativa. Estou orgulhoso de que o que vemos é a necessidade de colaboração por métodos mistos, mais do que apenas pensar que certos fenômenos relacionados à internet, filtros-bolhas ou à forma como funcionam as hashtags no Twitter só podem ser destacados pelo uso de metodologias quantitativas.

MATRIZes: Bem, mas se formos para os congressos internacionais, temos um problema aqui.

Waisbord: Certo. É um problema, e é uma luta constante, diria, em termos de como se reconhece e se apoia a diversidade, em vez de apenas priorizar certas abordagens epistemológicos ou métodos. Isso, para mim, é o que precisa ser feito constantemente nas conferências, nas organizações. As revistas científicas são diferentes, pois algumas possuem especialização em metodologias qualitativas ou quantitativas, mas, para mim, são as recorrentes dificuldades 
de se ter uma conversa aberta entre pessoas que trabalham com metodologias diferentes - isso é, para mim, parte do desafio. Mas, especialmente em um momento em que as pessoas acreditam que certos fenômenos relacionados à internet só podem ser analisados por meio de grandes conjuntos de dados ou análise computacional, então temos um problema. Porque o risco é fazer isso às custas de uma abordagem mais multiperspectivada e multimetodológica para quaisquer questões de pesquisa que tenhamos. Portanto, não digo isso como alguém que normalmente usa metodologias quantitativas, mas ao mesmo tempo reconheço algumas das virtudes de usar métodos computacionais. Para coletar dados sobre certas questões, e não há como negar que a questão é a suposição de que, na verdade, a única maneira de estudar certos fenômenos é usar certos métodos - é isso que não concordo.

MATRIZes: É claro que a pesquisa em comunicação e o conhecimento acadêmico devem repensar seus cânones e enfoques diante de uma coexistência pacífica entre fragmentação e digitalização. A formação acadêmica é um dos ramos importantes para a mudança. Em caso afirmativo, qual é a sua proposta como diretor de escola para um currículo de "comunicador contemporâneo"? Existe um meio-termo?

Waisbord: Acredito que a ideia deve ser expor os estudantes a essa tremenda diversidade dos estudos de comunicação, em vez da versão do currículo restrito - isso idealmente -, tanto na graduação quanto na pós-graduação. Creio que os estudantes de comunicação devem entender a variedade integral de questões. Não sou a favor da formação restrita, principalmente na graduação. $\mathrm{O}$ que quer que seja essa formação - em um conjunto de teorias, um conjunto de metodologias -, implementá-la não é tão fácil, porque é preciso ter pessoas no corpo docente que possam expor os alunos a uma ampla diversidade de tradições: tradições epistemológicas, de pesquisas teóricas.

Mas o esforço vale a pena, de novo, principalmente no nível de graduação. Há uma maneira relativamente simples de abordar isso. É possível fazer perguntas: nossos alunos estão tendo exposição suficiente à diversidade dos estudos de comunicação? O que está faltando em nossos currículos? O que não estamos ensinando? Ao que eles não estão sendo expostos? Os estudantes entendem o pensamento sobre a comunicação de formas diferentes - meios para fazer diferentes definições ou abordagens à comunicação? Então, essas são algumas questões para verificar se o currículo que temos é ou não suficientemente diversificado. Porém entendo que algumas escolas de comunicação se especializaram em determinados assuntos: algumas em estudos de mídia, outras em retórica ou semiótica. Mas acho que é importante ir além das áreas específicas 
de especialização de uma escola de comunicação. É importante fornecer uma compreensão ampla da comunicação, porque ela tem múltiplos significados.

MATRIZes: E isso nos leva à segunda questão sobre isso. Podemos dizer que os estudos da mediação digital poderiam ser um rótulo melhor para os estudos de comunicação contemporâneos? Ou a disputa entre a hiperespecialização e a ideia de objetos com significado global permanecerá?

Waisbord: Sim, em princípio é um nome interessante, já que vivemos na sociedade digital. A questão é que temos muitas opções e todas provavelmente capturam parte dos desenvolvimentos ou parte do que está acontecendo. Não acredito que qualquer conceito seja capaz de capturar tudo o que diz respeito à comunicação, porque há muita comunicação que não é digital. O que está acontecendo, pode-se argumentar, como mencionei anteriormente, é que a comunicação é mediação. Esse é um conceito que faz sentido, mas, novamente, teríamos que especificar o que queremos dizer, o que estamos incluindo, ou é deixado de fora, se usarmos "estudos de mediação digital" ou algo parecido. Ter um conjunto unificado de vocabulário não resolverá todos esses desafios crônicos que temos nos estudos da comunicação. Porque o vocabulário continua se expandindo, se multiplicando, existe outra Babel que continua crescendo, se tornando cada vez maior.

MATRIZes: Sua proposta de comunicação como uma pós-disciplina parece significativa em nossos tempos de pandemia, especialmente pelo uso contínuo do termo "pós-pandemia isso, pós-pandemia aquilo". Você acredita ser possível que a pesquisa em comunicação seja também uma disciplina necessária pós-pandêmica, especialmente a respeito de como as pessoas se comunicam (ou não se comunicam) em uma era cujo ambiente é marcado pela polarização política e pela digitalização crescente das atividades humanas?

Waisbord: A pandemia mostra exatamente a centralidade da comunicação e quão pouca comunicação é fundamental para isso. Pensando sobre isso, grande parte da pandemia tem sido uma resposta liderada por políticos, por especialistas em saúde pública, quando essencialmente, em termos de prevenção e resposta, a pandemia é um fenômeno de comunicação. E quão insuficiente tem sido essa centralidade, nos casos que conheço melhor, nos Estados Unidos ou na América Latina... Isso mostra porque a comunicação é tão importante: em qualquer aspecto da pandemia é possível encontrar relação com a comunicação. E as dificuldades de comunicação, todas as lacunas e falhas comunicativas, todas as suposições erradas sobre se alguma coisa a respeito da 
pandemia está mais ligada a uma abordagem informativa, hoje, do que uma da comunicação.

O que se tem são alguns governos ou agências tentando informar as pessoas sobre prevenção, segurança, vacinas e tudo mais, em vez de adotar uma perspectiva de comunicação, que é muito diferente da informação. A comunicação é basicamente sobre a compreensão. A informação é sobre transmitir dados ou conhecimento a outras pessoas - bem, isso não é comunicação. Mas muito da "assim chamada pandemia de comunicação" tem sido basicamente sobre a informação ou falta dela. Mas, especialmente, acho que você mencionou a questão da "polarização e digitalização", porque a maneira como a comunicação é feita está relacionada à polarização política, ao preconceito, aos vieses e todos os tipos de outros fatores dos quais precisamos de uma perspectiva de comunicação em vez de uma informacional. A informação é apenas, ou principalmente, sobre os dados, o conhecimento, a qualidade do que se transmite, em vez de envolver, trocar ideias com diferentes públicos - isso é comunicação. E não é de admirar que tenha havido tantos problemas ao longo do caminho. A pandemia, como todas as crises, é mais um exemplo de revelação de alguns dos processos fundamentais e dos problemas que temos em nossas sociedades - incluindo problemas de comunicação. Então, acredito que a pandemia é um mais amplo cenário concentrado para tudo o que já está acontecendo nas tendências da comunicação digital, e isso é o que vimos no ano passado.

MATRIZes: Você poderia explicar por que você diz que precisamos de uma análise pós-disciplinar para objetos multidisciplinares e complexos?

Waisbord: Temos tantos problemas sociais fundamentais ao redor do mundo, que acredito que a melhor maneira de se envolver nos estudos da comunicação é analisar a pesquisa, as ações em torno de problemas específicos. E isso a análise massiva pós-disciplinar e os estudos de comunicação já fazem. Basta pegar qualquer problema relacionado à violência. De certa forma, é possível assumir em todas as diferentes perspectivas da comunicação a análise da violência como um fenômeno social, político, interpessoal, relacionado ao local de trabalho. E é por isso que, em última análise, não importa qual é a origem disciplinar das ideias. $\mathrm{O}$ que se deve priorizar é a pergunta que explica o problema: quais são os aspectos de comunicação desse problema? Qualquer que seja o problema - ambiental, mudança climática, violência de gênero ou discurso de ódio -, cabe pensar sobre qual é a causa, como a comunicação ajuda a explicar o problema e a responder a ele. $\mathrm{O}$ que se diz - a análise, nesse sentido - mostra, então, a diversidade da comunicação como um recurso ao invés de um problema. 
Vislumbra-se uma perspectiva múltipla sobre a compreensão do que explica o problema, bem como quais são as soluções eficazes e viáveis. Isso para mim é uma forma mais produtiva do que revisitar todas as lutas, todas as batalhas nos estudos de comunicação - é uma forma de superar essas diferenças a respeito de questões ou problemas comuns -, independentemente de se fazer comunicação interpessoal, comunicação na internet, política, política de comunicação... O que quer que seja feito, quando se envolve com uma única questão, nesse momento, essas diferenças se tornam menos importantes do que poder pensar ou agir em conjunto sobre essas questões.

MATRIZes: E, por último - e, espera-se, não menos importante -, como você se autodefine como pesquisador e acadêmico de comunicação?

Waisbord: Para quem escreveu esse livro (Waisbord, 2019), tentei evitar rótulos. $\mathrm{Na}$ academia, os rótulos são muito importantes. É assim que nos mostramos aos outros em nossa autoapresentação à administração pública. Dizermos ser um estudioso do jornalismo, um estudioso da comunicação organizacional ou de semiótica. Mas, para mim, os rótulos não são muito úteis. Faço pesquisas, penso, escrevo. Não importa como me vejo. Sou formado como sociólogo, mas sou um estudioso de comunicação, trabalho na área de mídia. Faz alguma diferença na maneira como faço meu trabalho? Não, realmente! Porque estou interessado em perguntas e não em rótulos.

E, de certa forma, o que tentei fazer com os livros não é apenas mapear o estado dos estudos de comunicação, mas, ao fim, dizer que o que realmente importa é a questão em que se está interessado, não a sua identidade ou lealdade disciplinar. Quer dizer, parece-me que a recompensa acadêmica é certa licença para ser livre e criativo no modo como pensamos; não se trata de respeitar fronteiras e rótulos, respeitar disciplinas, embora todos sejamos formados em disciplinas, dentro de determinada abordagem, abordagens epistemológicas. Para mim, o que é muito mais interessante é "Qual é a sua pergunta?", “Como você pensa sobre isso?", em vez de "Isso é um estudo de comunicação ou não?”.

Mesmo que na academia tendamos a fazer isso, as revistas científicas fazem isso: os periódicos precisam dizer: "se meu journal é sobre comunicação política, não vou publicar algo sobre comunicação de saúde". Perfeito! Tive essa ideia ao ler sobre a maneira como os artistas pensam sobre arte e criação. Eles simplesmente criam, não pensam em si mesmos "Sou um pintor expressionista abstrato". Ou quando componho música, faço uma composição minimalista. Apenas crio, tento criar, pensar e, de certa forma, é isso que muitos de nós pensamos que fazemos. 
Defino-me como pesquisador e acadêmico de comunicação. Não gosto disso, porque a comunicação é muito flexível, mas ao mesmo tempo acho que dá bastante espaço para descobrir o que se quer saber, o que se quer escrever, o que se quer ensinar... De alguma forma que não seja limitada por "oh, isso vem da filosofia", "isso vem da literatura". Na verdade, o que sempre digo é que sou um estudioso da comunicação tentando ler o que está fora da comunicação, porque grandes ideias acontecem quando as coisas estão conectadas na academia. É possível ler um grande trabalho de biologia que o inspire a pensar sobre os estudos de comunicação! Ou ler poesia que o inspire sobre algo a respeito da comunicação. Isso para mim é uma noção melhor de um trabalho intelectual ou acadêmico do que simplesmente pensar em termos disciplinares, ainda que isso seja o que fazemos cotidianamente.

Portanto, é um equilíbrio entre estar alicerçado em certas tradições disciplinares, mas ao mesmo tempo ter a liberdade de pensar além dessas fronteiras convencionais. Porque essas são simples marcas, que de certa forma são artificiais. Quando ensino jornalismo, por exemplo, peço aos alunos que leiam literatura, ciência política, sociologia, filosofia, porque é um meio muito mais enriquecedor de compreender a história do jornalismo, a prática do jornalismo, assim é possível obter uma compreensão mais ampla de alguns dessas questões. $\mathbf{M}$

\section{REFERÊNCIAS}

Baudrillard, J. (2000). A transparência do mal: Ensaio sobre os fenômenos extremos. Papirus.

Tumber, H., \& Waisbord, S. (Eds.). (2021). The Routledge companion to media disinformation and populism. Routledge.

Virilio, P. (1993). Guerra e cinema. Página Aberta.

Waisbord, S. (2019). Communication: A post-discipline. Polity Press. https:// amzn.to/3enbIRD

Wieviorka, M. (2009). Violence. A new approach. Sage. 